Faculdade de Ciências Econômicas UFRGS
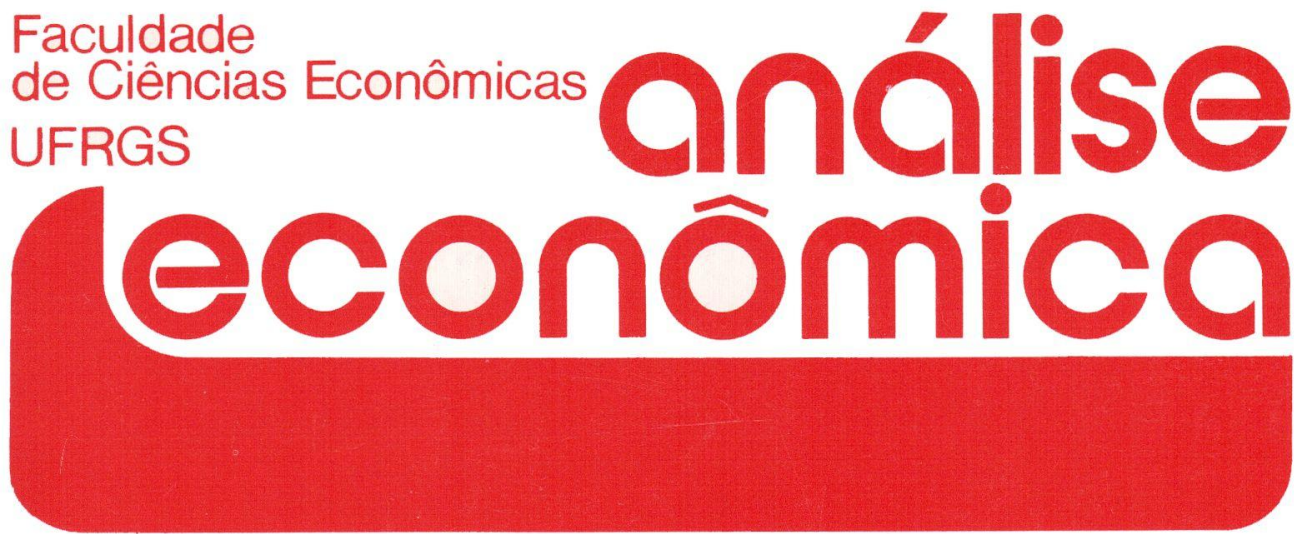

- STATE AND THE LIBERALIZATION OF THE BRAZILIAN ECONOMY

Carlos Alberto Longo

- MOEDA E CRÉDITO NA ECONOMIA BRASILEIRA: UM MODELO COM VETORES DE CORREÇÃO DE ERROS

Rolando M. Guzmán

- baSES PARA UM NOVO MOdELO DE POLítica FISCAL, PARA O BRASIL

Flávio Riani

- POR QUE OS SINOS DOBRAM? CONFLITO TRABALHISTA E SALÁRIOS DO MAGISTÉRIO PÚBLICO DO RIO GRANDE DO SUL, 1974-1991

Carlos Henrique Horn

Roberto Balau Calazans

- A POLÍtica MONETÁRIa E AS TAXAS de JUROS NO PLANO COLLOR

Lauro Lobo Burle

- DIFUSÃo E TRANSFERÊNCIA DA TECNOLOGIA DE PRODUÇÃO DE CIMENTO NO BRASIL

Maria Cristina Pereira de Melo

- SISTEMA FINANCEIRO BRASILEIRO: UMA PROPOSTA dE disCuSSÃo

Luiz Felipe Serpa

- TEORIA ECONÓMICA DO CASAMENTO E DO Divórcio

Giácomo Balbinotto Neto

- RESENHA

VARGAS: O CAPITALISMO EM CONSTRUÇÃO, DE PEDRO C. D. FONSECA

João Rogério Sanson

- LIVROS RECEBIDOS

Claudine Saldanha César
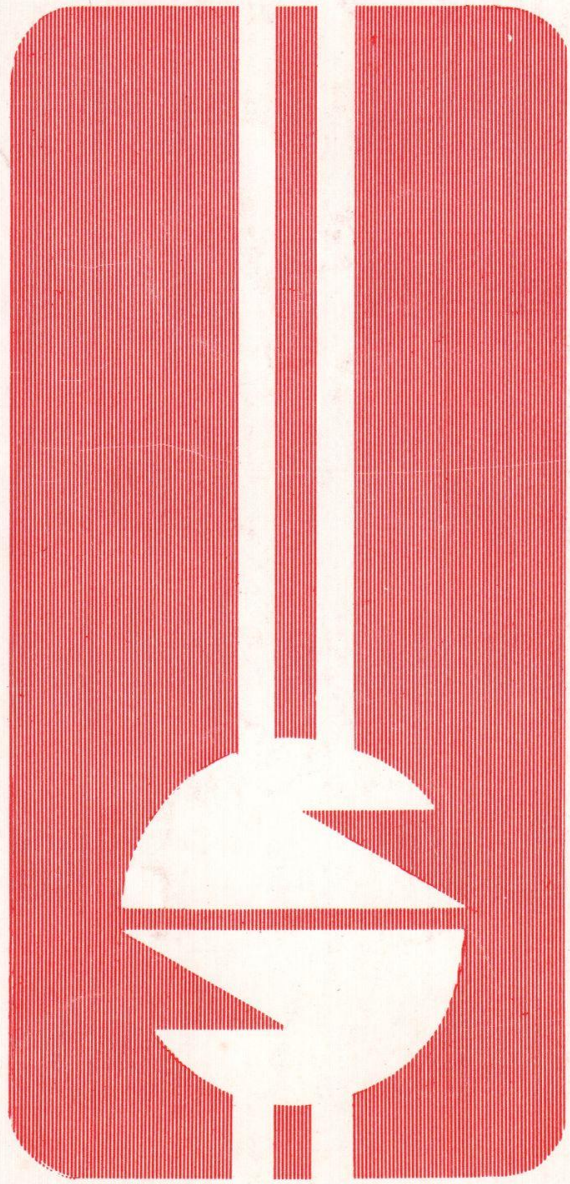
UNIVERSIDADE FEDERAL DO RIO GRANDE DO SUL

Reitor: Prof. Hélgio Henrique Casses Trindade

FACULDADE DE CIÉNCIAS ECONÔMICAS

Diretora: Prof ${ }^{a}$ Yeda Rorato Crusius

CENTRO DE ESTUDOS E PESQUISAS ECONÔMICAS

Diretor: Reinaldo Ignacio Adams

DEPARTAMENTO DE CIENNCIAS ECONÔMICAS

Chefe: Prof. Fernando Ferrari Filho

CURSO DE PÓS-GRADUAÇÃO EM ECONOMIA

Coordenador: Prof. João Rogério Sanson

CURSO DE PÓS-GRADUAÇÃO EM ECONOMIA RURAL

Coordenador: Prof. Juvir Luiz Mattuella

CONSELHO EDITORIAL: Achyles Barcelos da Costa, Aray Miguel Feldens, Atos Freitas Grawunder, Carlos Augusto Crusius, ErnaniHickmann, Fernando Ferrari Filho, João Rogério Sanson, Juvir Luiz Mattuella, Maria Imilda da Costa e Silva, Nali de Jesus de Souza, Nuno Renan Lopes de Figueiredo Pinto, Otília Beatriz Kroeĩ Carrion, Otto Guilherme Konzen, Paulo Alexaridre Spohr, Pedro Cezar Dutra Fonseca, Reinaldo Ignacio Adams, RobertsCamps Moraes, Valter José Stülp, Yeda Rorato Crusius, David Garlow (Wharton Econometrics Forecasts Association, E.U.A.), Edgar Augusto Lanzer (UFSC), Eleutério F. S. Prado (USP), Fernando Holanda Barbosa (FGV/RJ), Gustavo Franco (PUC/RJ), Joaquim Pinto de Andrade (UiNB), Juan H. Moldau (USP), Werner Baer (Univ. de Illinois, E.U.A.)

COMISSÃO EDITORIAL: Atos Freitas Grawunder, Reinaldo Ignacio Adams, Pedro Cezar Dutra Fonseca, Roberto Camps Moraes.

EDITOR: Nali Jesus de Souza

SECRETARIA: Maria Ivone de Mello (normalização), Vanete Ricacheski (revisão de textos)

FUNDADOR: Prof. Antônio Carlos Santos Rosa

Os materiais publicados na Revista Análise Econômica são de exclusiva responsabilidade dos autores. É permitida a reprodução total ou parcial dos trabalhos, desde que seja citada a fonte.

Aceita-se permuta com revistas congêneres. Aceitam-se, também, livros para divulgação, elaboração de resenhas ou recensões.

Toda correspondência, material para publicação (vide normas na $3^{a}$ capa), assinaturas e permutas devem ser dirigidos ao seguinte destinatário:

PROF. NALI DE JESUS DE SOUZA

Revista Análise Econômica

Av. João Pessoa, 52

90040-000 - PORTO ALEGRE (RS), BRASIL

Telefones: (051) 228.1633 - 224.6022 - Ramais 3348 ou 3440

FAX: (051) 225.1067 


\title{
BASES PARA UM NOVO MODELO DE POLÍTICA FISCAL PARA O BRASIL*
}

\author{
Flávio Riani**
}

\section{SINPOSE}

Este artigo procura discutir alguns pontos básicos que dêem sustentação a um novo modelo de política fiscal para o Brasil. Para tanto, é feita uma avaliação sobre o papel que deve ser desempenhado peio setor público, bem como sobre a atual estrutura fiscal brasileira. Finalmente, procuríi-se uma forma de atuação para o setor público e apresenta-se uma proposta de reformulação fiscal baseada em apenas quatro grupos de tributos.

\section{INTRODUÇÃO}

Dois anos e poucos meses após a última Constituiçãoo País começa a discutir novamente a questão do sistema tributário. Argumenta-se que o atual sistema é complexo e que onera sobremaneira as atividades produtivas. Na realidade, o que se percebe é que o sistema de tributação é de vital importância para a economia do País e, por isso, não se pode pensar em mudá-lo sem inseri-lo num contexto maior no qual esteja definido, inclusive, o papel que o governo deverá desempenhar neste nrocesso. Assim, pretende-se neste artigo levantar algumas questões sobre o atual sistema tributái io, sobre o papel a ser desempenhado pelo governo e contribuir para a concepção de uma estrutura tributária que seja mais moderna, complexa e que, acima de tudo, seja capaz de gerar receitas suficientes para que o governo possa exercer o seu papel.

- São de única responsabilidade do autor os pontos discutidos neste texto. Gostaria, no entanıo, de agradecer os comentários do Dr. Milion Campos Tavares da Assessoria Econômica e Tributária da Secretaria de Estado da Fazenda de Minas Gerais

** Diretor e professor da FACE - Fundação Universidade de Itaúna/MG. Assessor-Chefe da Assessoria Econômica e Tributária da Secretária de Estado da Fazenda de Minas Gerais. Técnico de Pesquisa da Fundação Joāo Pinheiro.

ANÁLISE ECONÔMICA

ANO $10 \quad \mathrm{~N}: 18$

SETEMBRO/92 P. $51-61$ 


\section{O ATUAL SISTEMA TRIBUTÁRIO}

Osistema tributárioembutidona Constituiçãode 1988 foi elaborado sem que houvesse qualquer discussão mais profunda sobre o papel do governo. Na realidade, havia, na época, um governo politicamente fraco, e as mudanças realizadas surgiram em função das mais diversas forças políticas. A argumentação básica para a mudança era a de que o sistema de arrecadação tributária era fortemente centralizado no governo federal e que o novo sistema deveria conter mecanismos que descentralizasse mais a arrecadação fiscal do País. Essa foi a tônica principal das argumentações para mudanças. Não houve em momento algum (ou se existiu partiu de uma minoria) propostas significativas que procurassem definir o papel do governo ou que tivessem a preocupação de corrigir os grandes desequilíbrios do sistema, principalmente of fato dele ser excessivamente regressivo. Assim, com uma grande pressão dos governadores e principalmente dos prefeitos, foram feitas então as mudanças no sistema tributário em 1988 com oúnicoobjetivo de procurar descentralizar os recursos fiscais. Com isso, diminuiramse os tributos de competência tributária da União, ampliou-se o ICM para ICMS e deu-se aos municípios novos impostos. Além disso, alteraram-se os critérios de rateio do bolo fiscal, aumentando os recursos dos Fundos de Participação de Estados e Municípios e dando aos municípios um acréscimo real de $25 \%$ na sua participação relativa no produto do ICMS. Hoje muitos estados lamentam a insuficiência de recursos ganhos com a reforma, face aos acréscimos nos seus encargos (alguns oriundos da "Operação Desmonte" e outras das mudanças nas Constituições Estaduais), e a grande maioria dos municípios não sabe como aplicar os $25 \%$ das suas receitas em educação em face do excessivo volume de recursos.

A sociedade, por sutro lado, reclama pela falta de organização e de transparências, pela absoluta carência dos serviços públicos essenciais, pela distribuição injusta da carga tributária, que onera as classes de renda mais baixa; os empresários e o setor produtivo privado reclamam da eleváda carga tributária (que, aliás, a do Brasil é uma das menores do mundo sendo hoje em torno de $24 \%$ do PIB), da falta de controle dos gastos do governo e pedem, insistentemente, que seja diminuído o tamanho do Estado.

De fato, a estrutura tributária atual é por demais complexa. Existe hoje um total de 57 tributos entre taxas, impostos, contribuições, etc. Cada um deles possui uma legislação própria e complexa que exige dos setores produtivos uma estrutura administrativa composta de várias pessoas e de vários especialistas. Por tudo que se sabe, parece óbvio que o sistema poderia ser simplificado. Esta simplificação, portanto, requer que a discussão dessas mudanças seja acompanhada de uma apreciação maior sobre o papel do governo. É em função dessa avaliação que se definirá qual a carga tributária necessária e qual a moldura a ser dada ao sistema fiscal de modo que ele forneça os recursos para que o governo exerça com eficiência o papel que lhe for dado. 


\section{O PAPEL dOS gaSTOS PÚBL.ICOS}

Depois da Segunda Guerra Mundial acreditava-se que o único meio de se conseguir um maior crescimento econômico e um melhor desenvolvimento social seria através de uma intervenção maciça das ações governamentais na economia. Por esse motivo, o setor público cresceu rapidamente em quase todo o mundo, principalmente nos países em desenvolvimento. Na maioria dos casos, a atuação governamental foi fundamental para a realização de investimentos em infraestrutura básica, devido sobretudo, à relutância do setor privado em assumir o papel preponderante na promoção dos investimentos e do crescimento. Por essa razão, na grande maioria desses países, os gastos governamentais, que antes da Segunda Guerra Mundial não atingiam a $10 \%$ do PIB, alcançarem cifras superiores a $30 \%$ e $40 \%$ já na década de 80 . Houve, portanto, nesses últimos 40 anos, uma significativa expansão desses gastos e foram inúmeras as empresas e órgãos criados pelo setor público. Dessa forma, a política de crescimento baseada nas ações dos governos fez com que houvesse um processo contínuo de aumento nos gastos públicos combinado com uma grande intervenção do Estado na economia.

Inegavelmente, as ações governamentais tiveram nas últimas décadas um importante papel no crescimento estruturação das economias capitalistas, principalmente as menos desenvolvidas. Os investimentos públicos foram fundamentais para o crescimento do capital físico dos diversos países, tiveram um papel relevante no crescimento e na formação do capital humano e contribuíram decisivamente para que houvesse avanços tecnológicos e mudanças no uso mais eficiente dos recursos da economia.

Acontece, porém, que a partir do início da década de 80 , devidoàs sucessivas crises no mercado mundial, às crises do petróleo e à falta de ajustamentos interrios na economia de um grande número de países, o setor público passa de uma situação de redentor da atividade econômica para uma de problema e de empecilho para ocrescimentoe para o equilíbrio das economias, principalmente as subdesenvovidas e em desenvolvimento. Devido à falta de ajustamentos, muitos países viram o déficit do setor público atingir níveis insustentáveis iá no início da década de 80 . A permanência desta situação deficitária contribuiu para que esses países absorvessem um pesado endividamento externo acompanhado de elevadas taxas inflacionárias.

Porém a extinção dos créditos externos em meados da década de 80 , já era um sinal de que o déficit público não poderia ser financiado por essa fonte e que era indispensável que houvesse um maior controle por parte dos governus. Apesar disto, muitos países insistiram no desequilíbrio fiscal cujo déficit passou a ser financiado não pelos recursos externos, mas sim através da emissão de moeda e de lançamentos de títulos públicos. Essa atitude dos governos trouxe para seus respectivos países um sério problema de descontrole inflacionário. Assim, no final da década de oitenta e início dessa década, a grande preocupação de uma enorme parte de países subdesenvovidos e em vias de desenvolvimento voltou-se para $o$ 
combate ao déficit público e para tentativas de eliminação do acelerado ritmo inflacionário.

Dessa forma, o grande desafio encontrado tem sido o de buscar alternativas para que esta contenção do déficit e da inflação não implique um processo recessivo violento e não prejudique as perspectivas de desenvolvimento de médio e longo prazos. Para tanto, há a necessidade de um ajustamento fiscal adequado de forma que as variações simultâneas de receitas e despesas minimizem os seus custos econômicos e sociais.

Neste contexto, a discussão sobre o papel a ser desenvolvido pelo setor público passa a ser de vital importância. É através dessa definição que se poderá estabelecer as atividades a serem desempenhadas pelo governo e poderá, também, ser montada uma estrutura tributária adaptada a esta nova política de participação governamental.

No que se refere aós gastos públicos, o problema crucial para definição de seu papel é o de se buscar equilíbrio entre suas atividades produtivas e sociais ou até mesmo optar por uma delas. Isto porque, de forma ou de outra, essas atividades ainda exercerão um papel importante no processo de crescimento.

Uma das opções de atuação do governo poderá ser a de criar condições básicas para que o país possa crescer. "Neste caso a maior parcela dos gastos públicos se voltaria para investimentos de grande escala, como projetos de infraestrutura básica, que dificilmente seriam realizados pelo setor privado. Nesta opção, seguramente agravar-se-ão os problemas nas áreas sociais, uma vez que menores serão as quantidades de recursos públicos disponíveis a serem a elas destinadas. Além disso, seria preciso também que ogovernodispusesse de recursos próprios suficientes para gerarem as poupanças requeridas para tais investimentos. Este seguramente não é o caso da grande maioria dos países, especialmente os subdesenvolvidos e em desenvolvimento.

A outra alternativa seria a de se orientar as ações do governo prioritariamente para atividades de infra-estrutura social básica. Com isto, grande parte dos investimentos e gastos governamentais seriam destinados às atividades sociais como saúde, educação, etc.

A terceira alternativa seria buscar um equilíbrio entre as op̧̧̃es acima. Ou seja, a op̧̃ão não seria por uma ou outra hipótese, mas sim por uma forma de participação que envolvesse os dois casos. Qual seria então a opção para o Brasil, no momento?

Quando se analisa o processo dos gastos públicos no Brasil, percebe-se que uma parcela proporcionalmente maior foi destinada a atividades que, de uma forma ou de outra, sempre beneficiaram o setor produtivo da economia. Aliás, a história brasileira mostra que, já no período da agricultura cafeeira, todas as ações governamentais visavam à prosperidade econômica desse setor. Quando se deu início do processo de substituição das importações, o país, através da ação governamental, criou, sob sua responsabilidade financeira, uma série de órgãos e 
de atividades básicas para que o crescimento da economia brasileira fosse alcançado. Este processo de intervenção governamental tem início com a aquisição das antigas linhas ferroviárias inglesas, pela implantação da Companhia Siderúrgica Nacional, pelos Bancos de Desenvolvimento e chega no início dos anos $60 \mathrm{com}$ a implantação de vários monopólios estatais na área de energia elétrica, comunicações, petróleo, etc. Com a revolução de 1964 e em todos os governos que a representaram, a opção continuou sendo a de priviligiar o capital e o crescimento econômico em detrimento do desenvolvimento social e do trabalho. A idéia era a de que dever-se-ia primeiro buscar o crescimento do bolo econômico para depois então distribuí-lo. Com este objetivo, o governo investiu com recursos próprios e com poupança externa em uma série de projetos sobre os quais grande parte das atividades produtivas brasileiras se apoiaram para se desenvolver. Além disso, o governo criou uma série de subsídios e incentivos fiscais que beneficiaram sobremaneira o setor produtivo privado.

Todo este aparato "institucional" conseguiu durante algum tempo fazer com que os objetivos do crescimento econômico fosse alcançado. Haja vista que a taxa de crescimento médio da economia brasileira na década de 70 superou os $12 \%$ anuais.

Se, inegavelmente, este crescimento foi alcançado, o mesmo não se pode dizer do desenvolvimento social. A distribuição tão esperada do bolo econômico nunca aconteceu. Aliás, os indicadores mostram que, após a Revolução de 1964, o nível de concentração da renda aumentou significativamente. Além disso, o processo de crescimento econômico centralizou-se nas grandes cidades, causando com isto uma imensa aglomeração humana nessas regiões. Essas, por sua vez, já não dispunham de uma infra-estrutura social e urbana adequada que foram se deteriorando ainda mais com esta concentração.

Dado o fato de que a prioridade goveriamental era com o crescimento, pouco se fez, de concreto, em relação às áreas sociais. Até por uma questão financeira, isto não foi possível. Na medida em que num universo restrito de obtenção de receitas tributárias, gasta-se mais num setor, o outro é automaticamente prejudicado. Isto foi o que ocorreu com praticamente todos os serviços sociais dic responsabilidade direta do governo.

Na década de 80, em geral, todos os tipos de gastos governamentais, tanto na área social quanto na produtiva, foram significativamente comprometidos devido à falta de poupança governamental e às restrições de obtenção de recursos externos. Além disso, as finanças públicas entraram num processo de completa deterioração. Grande parte das receitas públicas destinava-se aos gastos com custeio e o governo entrou num processo de rolagem da dívida, sobretudo a mobiliária, devido à impossibilidade dele arcar com os encargos financeiros oriundos do seu processo deliberado de endividamento. Assim, neste processo de completa deterioração das finanças públicas, o país vê a diminuição e a retirada do governo da economia como uma alternativa viável de reequilíbrio. 
Dentro entãodessa situação caótica que se encontra o país, seria possível esta retirada abrupta do governo da economia? Quais seriam as novas funções para o setor público brasileiro?

Na realidade, a economia brasileira, como todas as economias subdesenvolvidas e em desenvolvimento, necessita de uma participação ativa do setor governamental nas áreas de infra-estrutura econômica básica. Até porque, pelas características do Brasil, dificilmente o setor privado, pelos riscos econômicos, investirá nessas atividades. Dentre os setores que se enquadram nesta situação podemos citar o de transportes (estradas), energia elétrica, comunicações, em alguns casos o próprio setor siderúrgico, a água, o saneamento, etc. Assim, pela importância que esses setores desempenham no crescimento econômico e no desenvolvimento social, é praticamente impossível de se pensar na retirada do governo dessas atividades se se quer alcançar os objetivos mencionados de crescimento. Dessa forma, o que precisa ser feito é estabelecer um processo seletivo que determine as áreas e as prioridades do país, nos quais a participação do governo é exigida, e aí, então, retirar o setor público de atividades não prioritárias. É ilusão pensar que, no caso brasileiro,é possível abolir a participação do governo em setores de infra-estrutura básica para quaisquer perspectivas de crescimento econômico que se deseje.

Do ponto de vista das atividades sociais do Estado, a situação é dramática. Conscientemente nenhum governante deveria ter a redução dos gastos nas áreas sociais como alternativa de resolver ou minimizar os problemas financeiros do governo. Na realidade, muito pouco se gastou nestas atividades, cujas demandas cresceram e crescem em proporções geométricas. É indispensável que o governo tenha como meta de curtíssimo prazo recuperar e reequipar os serviços sociais básicos, teoricamente, a ele subordinados. É inconteste a deterioração de praticamente todos os serviços sociais básicos. Dessa fornia, é impensável que o governo adote ainda a contenção de gastos e de investimentos nessas áreas como alternativas para solução dos seus problemas financeiros. Por um longo período de tempo, o governo terá ainda que intervir e gastar recursos na provisão de serviços educacionais, de saúde, de habitação, vias públicas, água, etc. No trcante aos serviços urbanos, é crucial o envolvimento dos gastes governamentais para a solução de seus problemas.

Planejar os gastos de uma maneira geral, e no setor público em particular, é uma questão de prioridade. Todos os projetos de investimentos governamental, seja ele econômico, técnico, administrativo, financeiro ou social, precisam ser bem planejados e implementados num contexto de políticas que propicie incentivos a um bom desempenho econômico e social. Visto dessa forma, é prioritário que o governo implemente mudanças estruturais na economia brasileira e no seu próprio aparato administrativo e institucional. É indispensável, porém, que nos próximos anos, o governo no Brasil priorize seus investimentos em infra-estrutura básica indispensável ao crescimento do país e estabeleça no curto e médio prazos 
um programa de investimentos em áreas básicas. O país não poderá optar apenas por uma ou outra alternativa.

Paralelamente a essa política de gastos, o Governo deveria promover uma alteração no seu sistema tributário a fim de torná-lo mais eficiente, menos complexo e mais justo.

\section{BASES PARA UMA NOVA ESTRUTURA TRIBUTÁRIA}

Conforme foi mencionado anteriormente, a estrutura tributária brasileira é composta por um conjunto de 57 tributos. Desse total, mais de 30 correspondem a taxas cobradas pelos três níveis de governo (no conjunto não atingem a $2 \%$ do PIB), existe um outro tanto de contribuições e um número até que reduzido de impostos.

Embora a quantidade de tributos seja elevada, a sua qualidade é a pior possível, em todos os sentidos. Da mesma forma que eles são regressivos e desincentivam a produção, são também, pelo seu número, ineficientes na geração de recursos. Estima-se que hoie a carga tributária no país seja de $24 \%$ do PIB. Essa carga é relativamente baixa se comparada aos padrões internacionais e com base nesses mesmos parâmetros extremamente injusta. Para se ter uma idéia, enquanto a carga tributária brasileira é a acima citada, nos Estados Unidos ela atinge 32\%, na França 47\%, Canadá 39\% e nos países escandinavos ela chega a mais de $50 \%$. Na grande maioria dos países desenvolvidos, ela é bem superior à do Brasil. Por outro lado, enquanto nesses países a média dos impostos indiretos no total dos tributos é de $27 \%$, no Brasil ela chega a 54\%. Assim, visto somente pelo ângulo das comparações internacionais, percebe-se que a carga tributária brasileira é bem inferior à de outros países, porém com uma distribuição extremamente injusta.

Assiin, a análise da carga tributária não deve ser feita apenas com base nesses parâmetros. É também de suma importância que se analise os dados dos gastos governamentais para que se possa, então, avaliar o real peso da carga tributária. Visto por este ângulo, parece nỗo haver nenhuma dúvida de que a carg? tributária urasileira, anesar do seu ürercentual relativo no PIB ser inferior à dos países citados, acaba sendo extremamente elevara. Ela é, assim, devido às grandes ineficiências verificadas em todas as áreas que são supostamente de responsabilidade de atuação do governo. Hoje no Brasil estão praticamente falidas as instituições públicas de ensino e de saúde, o déficit habitacional é alarmante, a infra-estrutura social, urbana e econômica está deteriorada, enfim, são poucas as atividades do governo que são mais ou menos eficientes. Daí a razão pela qual deve-se moldar uma nova forma de atuação para o governo e uma estrutura alternativa de tributação que tenha, não necessariamente uma carga mais baixa, mas sim mais bem distribuída entre as várias camadas da sociedade. De qualquer forma, independentemente do papel a ser dado ao governo e do nível da carga tributária que se pretende, acredito que o sistema fiscal brasileiro poderia ser significativamente simplificado. Entendo que deveria compor um novo sistema um grupo de quatro tipos de tributos. 
O primeiro grupo seria composto das diversas taxas cobradas hoje no país. Critica-se muito a sua quantidade, mas esquece-se das suas especificidades e até mesmo da sua função. As taxas são, por natureza, o pagamento a um benefício específico prestado a um indivíduo na sociedade. Ou seja, ela é uma contrapartida a um serviço prestado. Dessa forma, ela só será paga por alguém que requerer do governo (Federal, Estadual ou Municipal) um serviço específico. Assim, muitos elementos na sociedade não têm o ônus desses tributos já que a grande maioria deles não requerem esses tipos de serviços. Visto por esse ângulo, as taxas representam um instrumento a mais de controle de serviços e na realidade pouco contribuem ou pesam na carga tributária total. Conforme foi dito, apesar da sua quantidade, elas representam menos do que $2 \%$ do PIB. Assim, por sua função reguladora de serviços e pela sua condição de vinculação ao benefício recebido, acredito que a sua manutenção é extremamente justificável. Do ponto de vista funcional, o seu número é irrelevante. Da mesma forma que existem mais de 30 taxas, este número poderia ser reduzido ou até mesmo ampliado, em face das diversas especificidades locais e regionais dos serviços a serem requeridos.

Num país com as grandes desigualdades de distribuição da rendae da riqueza como o Brasil, o Imposto sobre a renda e o patrimônio são fundamentais para se tentar diminuir essas disparidades. Além do mais, é através desse imposto que se pode tornar um sistema tributário mais justo. Existem várias argumentações, inclusive a dos defensores do imposto único sobre transações financeiras, de que, na realidade, o imposto de renda no Brasil não é progressivo e que, portanto, deveria ser substituído.

No meu entender a questão não é substituir o imposto de renda e do patrimônio, mas sim buscar formas alternativas e criativas de aperfeiçoá-los. Indiscutivelmente, hoje no país, o imposto de renda tem sido mais ou menos eficiente apenas com a tributação sobre os rendimentos assalariados. As outras formas de obtenção de renda estão completamente fora de controle de fiscalização, o que contribui para que a evasão de tributos seja violenta e que, com isto, este sistema se torne também injusto. Dessa forma, o governo deveria tentar ao máximo aprimorar suas técnicas de contrcì e sua legislação a fim de tornar este imposto mais justo e com uma contribuição de receita muito acima do que se arrecada hoje. Por exemplo, se exigisse que, em todas as transações de bens móveis e imóveis, fosse necessário que as parte envolvidas apresentassem uma certidão de posse do imóvel obtida através das declarações de renda junto à receita federal, mesmo que aumentasse um pouco a burocracia, isto certamente contribuiria para um melhor controle de arrecadação.

O fato é que o imposto de renda bem administrado pode exercer um papel fundamental tanto como gerador de receitas públicas quanto de mecanismo de diminuição da concentração da renda e da riqueza.

$\mathrm{O}$ imposto sobre o patrimônio vem ao longo de vários anos sendo mal administrado e, por isso, a sua efetiva contribuição acaba sendo irrisória. $\mathrm{Na}$ realidade, este imposto vem sendo administrado e cobrado pelos municípios. As 
administrações locais, por questões políticas, evitam ao máximo fazer as correções nos valores desses imóveis em consonância com o desempenho inflacionário e também em função da valorização dos imóveis por questões específicas locais. Isto tem contribuído para que a geração de receitas tributárias dessas fontes seja bem abaixo do seu verdadeiro potencial. Pelas características desse imposto, nota-se, também, que a sua semelhança com o imposto de renda, no que se refere a capacidade de aumentar a receita e ser um instrumento de buscar um sistema tributário mais justo, é muito alta. Na realidade, ele exige também aperfeiçoamentos e mecanismos legais que impeçam a sua utilização como instrumento de demagógica política local.

O terceiro tipo de imposto a ser cobrado deveria ser o Imposto sobre o Consumo Final de Bense Serviços. Na realidade, quando se observa o atual sistema tributário, nota-se que a sua maior complexidade e duplicidade encontra-se no grande número de impostos que incidem sobre a atividade de produção e de comércio. Isto além de tornar a administração fiscal mais difícil, tumultua os contribuintes na medida em que se exige das diversas atividades econômicas um razoável aparato administrativo apenas para apuração fiscal e acompanhamento das legislações pertinentes. Dessa forma, um único imposto cobrado sobre o consumo final de bens e şrviços eliminaria por completo a complexidade do sistema, além de tornar a sua fiscalização muito mais eficiente. Aliás, esse é o mecanismo utilizado em grande parte dos países dá Europa.

Assim, como no caso do Imposto sobre Renda e Patrimônio, este imposto poderá causar distorções e concentrações de arrecadação em regiões específicas. Porém este é um problema de fácil solução, na medida em que através de discussões até no mesno Congresso pode se chegar a uma fórmula balanceada de distribuição do bolo tributário e de um mecanismo de transferências inter e intragovernamental que dê uma melhor equalização na repartição do seu produto.

O quarto e último grupo de impostos relaciona-se aos tributos incidentes sobre o comércio exterior. Os İmpostos de Importação e de Exportação são muito mais importantes como instrumento de política econĉmica do que como fonte de arrecadação tributária. Portanto é crucial que o governo disponha desses rıecanismos para ut:lizá-los, quando necessário, como instrumento regulador do comércio com o exterior.

\section{CONSIDERAÇÕES FINAIS}

Nesta última parte, será considerado o papel dos gastos públicos, alterações e simplificação tributária e a participação do setor privado nos ajustes governamentais.

Pelos pontos analisados anteriormente fica claro que existe hoje uma necessidade premente de reformulação na política dos gastos públicos, no sistema tributário e na atitude do setor produtivo privado. 
Diferentemente do que se imagina, os gastos públicos ainda exercerão um papel fundamental em qualquer política de crescimento econômico que se estabeleça para o país. Por essa razão é preciso prever uma parcela razoável de recursos para este tipo de investimento. Além disso, haveria necessidade também de mais receitas fiscais a fim de que o governo tenha recursos suficientes para gastos em investimentos sociais. Assim, prevê-se para o curto e médio prazo um misto de gastos em áreas sociais e de gastos em investimentos de infra-estrutura econômica básica.

As alterações propostas para o sistema tributário têm duas vantagens fundamentais. A primeira delas é a sua simplificação. A redução da tributação em apenas quatro grupos de impostos facilitará o seu controle e fiscalização. A segunda é que através desses grupos abre-se a oportunidade de aumentar a receita tributária sem, contudo, aumentar a sua carga. Para tanto, basta que se modernize e dinamize o controle, os métodos e a fiscalização pela receita federal através de mecanismos mais eficientes de trabalho. A alternativa da certidão de posse de imóveis expedida pela receita para transações de bens móveis e imóveis pode ser uma das formas de melhorar o controle. Assim, os impostos sobre o patrimônio e a renda aperfeiçoados poderão exercer papel importante na elevação das receitas tributárias e na diminuição das injuş̧̧̧⿻̧一 nas na distribuição de sua carga entre os indivíduos na sociedade. O Imposto sobre o Consumo de Bens e Serviços, poderá ser seletivo ou não, e poderá ter a sua carga tributária definids e in função da política de gastos do governo e em função dos recursos arrecadados via imposto sobre a renda e o patrimônio. Em função dessas mudanças é provável que haja um aumento geral nas receitas fiscais sem, contudo, aumentar a carga tributária, na medida em que, com o Imposto sobre o Consumo Final de Bens e Serviços, todo o universo de consumo por ele atingido, o que seguramente poderia acarretar uma significativa redução na taxa de evasão.

É importante também destacar que o setor produtivo privado poderá dar uma grande contribuição para a melhoria da atuação governamental. O setor privado, através de um pensamento mais moderno precisa entender que opjroblema dos seus empregados reflete dentro das suas próprias atividades. Assim, através de melhoria de salátio e da criação de várias atividades de assistência de saúde, educacional, habitação, etc., o setor privado poderá contribuir decisivamente para que diminua a pressão social e a demanda existente hoje sobre o setor público. Poderia haver, inclusive, um mecanismo de incentivos governamental em alguns desses casos. É preciso que o setor produtivo entenda, que o problema social do país é também um prcblema seu. Um programa de melhorias salariais além de tornar os empregados mais eficientes ampliará também o próprio mercado interno através do aumento de demanda. Enquanto não se entender que o grande problema do Brasil passa pelo elevado índice de concentração de renda e da riqueza, e que os problemas deixados apenas para o setor público resolver são infinitamente superiores à sua capacidade de atuação, em face das limitações financeiras, dificilmente veremos um pais socialmente mais justo. Assim, se houver uma mudança no comportamento do 
setor produtivo aos moldes citado, se houver uma racionalidade maior na política de gastos públicos e se as reformas fiscais forem feitas de forma a tornar mais justo o sistema tributário e diminuir a evasão, o governo será capaz de gerar poupanças necessárias para desempenhar a contento suas funções. Isto facilitaria inclusive o equacionamento da sua dívida interna e externa, que, aliás, são dois outros pontos de grande estrangulamento que enquanto não forem resolvidos, impedirão, com certeza, o processo de retomada do crescimento da economia brasileira.

\section{BIBLIOGRAFIA}

BAER, W. et alii. As Modificações no Papel do Estado na Economia Brasileira. Pesquisa e Planejamento Econômico, Rio de Janeiro: IPEA/APLAN, v.3, n.4, p.883-912, dez. 1973.

DIAMOND, J. Gastos Públicos e Crescimento. Finanças e Desenvolvimento, Washington: FMI/BIRD, v. $10, n^{\circ} 4$, p. 34-36

GRAY, C.W. \& L.INN, J. F A Melhoria das Finanças Públicas e o Desenvolvimento. Finanças e Desenvolvimento, Washington: FMI/BIRD, v.8, $n^{9} 3, p .2-5$, set. 1588.

HEMMING, R \& KOCHHAR K. Políticas Fiscais com Vistas ao Crešimento. Finanças e Desenvolvimento, Washington: FMI/BIRD, v. 10, n², p.37-39, dez 1990.

L.OZARDO, E. As Raízes da Crise Econômica Carta Andina, Rio de Janeiro, p.4-9, nov. 1989.

RIANI, F. Economia do Setor Público. Uma Abordagem Introdutória 2 ed São Paulo: Atlas, 1990.

\section{ABSTRACT \\ BACKGROUND FOR A NEW TAX MODEL TO BRAZIL}

This article tries to dicuss some basic issues aiming at building the background of a Brazilian taxation system Therefore, an evaluation on the role that public setor must carry on as well as on the Brazilian fiscal structure, is done. In conclusion. the artice strives for defining a way of performance tor the public sector and suggests a new taxation system basead on only four groups of taxes. 